\title{
Vibrio spp. isolados de mamíferos marinhos capturados na região litorânea do sudeste ao sul do Brasil ${ }^{1}$
}

\author{
Christiane S. Pereira ${ }^{2 *}$, Simone D. Amorim² ${ }^{2}$, André F.M. Santos ${ }^{2}$, Salvatore \\ Siciliano ${ }^{3}$, Ignácio M.B. Moreno ${ }^{4}$, Paulo H. Ott ${ }^{5}$ e Dalia P. Rodrigues ${ }^{2}$
}

\begin{abstract}
Pereira C.S., Amorim S.D., Santos A.F.M., Siciliano S., Moreno I.M.B., Ott P.H. \& Rodrigues D.P. 2007. [Vibrio spp. isolated from marine mammals captured in coastal regions from southwestern to southern Brazil.] Vibrio spp. isolados de mamíferos marinhos capturados na região litorânea do sudeste ao sul do Brasil. Pesquisa Veterinária Brasileira 27(2):8183. Laboratório de Enterobactérias, Departamento de Bacteriologia, Pavilhão Rocha Lima, Instituto Oswaldo Cruz, FIOCruz, Av. Brasil 4365, Rio de Janeiro, RJ 21045-900, Brazil. E-mail: csoarespereira@hotmail.com

In the present investigation was evaluated the incidence of Vibrio spp. from superficial lesions at marine mammals beached or captured by fishing net in the southwestern (RJ) and southern (RS) coastal regions of Brazil. One hundred and ninety eight swabs were collected by DEENSP, GEMARS and Ceclimar institutes and sent to Labent/IOC/FIOCruz where the samples were submitted to enrichment in Alkaline Peptone Water (APW) added with $1 \%$ and $3 \%$ of sodium chloride $(\mathrm{NaCl})$ incubated at $37^{\circ} \mathrm{C}$ for $18-24$ hours. After the samples were streaked onto Thiossulfate Citrate Bile Sucrose Agar (TCBS), the suspected colonies were submitted to biochemical characterization. The results showed 108 strains, and Vibrio alginolyticus, $V$. parahaemolyticus, $V$. vulnificus and $V$. fluvialis were the main pathogens isolated. These results appoint the importance of surveillance and microbiological monitoring accomplishment and reinforcement of environmental protective programs applied to marine mammals endangered with extinction.
\end{abstract}

INDEX TERMS: Vibrionaceae, aquatic ecosystem, public health.

RESUMO.- Avaliou-se a incidência de Vibrio spp. a partir de lesões superficiais em mamíferos marinhos encalhados ou capturados em redes de pesca nas regiões litorâneas do Sudeste (Rio de Janeiro) e Sul (RS) do Brasil. Foram coletadas 198 amostras, pelas instituições de pesquisa DEENSP, GEMARS e Ceclimar, as quais foram enviadas ao Labent/IOC/FIOCruz,

\footnotetext{
${ }^{1}$ Recebido em 13 de novembro de 2006.

Aceito para publicação em 5 de fevereiro de 2007

${ }^{2}$ Laboratório de Enterobactérias, Departamento de Bacteriologia, PaviIhão Rocha Lima, Instituto Oswaldo Cruz, FIOCruz, Av. Brasil 4365, Manguinhos, Rio de Janeiro, RJ 21045-900, Brazil. *Autor para correspondência: csoarespereira@hotmail.com

${ }^{3}$ Departamento de Endemias, Escola Nacional de Saúde Pública Sérgio Arouca, ENSP/FIOCruz, Rua Leopoldo Bulhões 1480, Manguinhos, Rio de Janeiro, RJ 21041-210.

${ }^{4}$ Grupo de Estudos de Mamíferos Aquáticos, GEMARS, Rua Felipe Neri 382, Apto 203, Porto Alegre, RS 90440-150.

${ }^{5}$ Centro de Estudos Costeiros Limnológicos e Marinhos, Ceclimar/UFRGS, Av. Tramandaí 976, Imbé, RS 95625-000.
}

onde foram submetidas ao enriquecimento em Água Peptonada Alcalina (APA) adicionada de $1 \%$ e $3 \%$ de $\mathrm{NaCl}$ e incubadas a $37^{\circ} \mathrm{C}$ por $18-24$ horas. Em sequiência foram semeadas em meio Agar Tiossulfato Citrato Bile Sacarose (TCBS) e as colônias suspeitas submetidas à caracterização bioquímica. Foram isoladas 108 cepas bacterianas, destacando-se Vibrio alginolyticus, V. parahaemolyticus, $V$. vulnificus e $V$. fluvialis como os principais patógenos isolados. Os resultados obtidos apontam para a necessidade de implementar atividades de vigilância e monitorização bacteriológica, particularmente de espécies selvagens, e reforçar os programas de proteção ambiental em casos de mamíferos marinhos ameaçados de extinção.

TERMOS DE INDEXAÇÃO: Vibrionaceae, ecossistema aquático, saúde pública.

\section{INTRODUÇÃO}

O ambiente marinho é reconhecido como habitat de microrganismos, alguns dos quais patogênicos para o homem e ani- 
mais. Membros da família Vibrionaceae podem afetar negativamente o nicho ecológico de mamíferos marinhos, ocasionando sérias implicações para sua saúde. Entretanto, estudos acerca da identificação do agente etiológico e seu potencial de risco para espécies marinhas, especialmente aquelas ameaçadas de extinção, podem ser dificultados pelo hábito migratório destes animais (Thompson et al. 2004).

No Brasil, estudos têm demonstrado a presença de Vibrio spp. no ecossistema aquático, lesões cutâneas em pescadores e a partir de alimentos de origem marinha (pescados) caracterizando seu envolvimento em casos de doenças de transmissão alimentar (DTA). Profissionais do ramo da pesca, mergulhadores e manipuladores de alimentos representam grupo de risco nas infeç̧ões causadas por vibriões (Rodrigues et al. 1992, Rodrigues et al. 2001, Pereira 2003). Alguns destes microrganismos são considerados oportunistas e em hospedeiros saudáveis podem fazer parte da microbiota de animais aquáticos, inclusive aqueles criados em condição de cativeiro ou sistemas de aquiicultura. Tais animais, entretanto, quando submetidos a condições de estresse, ficam suscetíveis aos microrganismos, aumentando assim a frequiência de enfermidades sistêmicas ou localizadas (Johnson et al. 2006).

Na presente investigação objetivou-se avaliar a presença de Vibrio spp. em lesões de mamíferos marinhos capturados acidentalmente por redes de pesca ou encalhados em bancos de areia nas regiões litorâneas dos estados do Rio de Janeiro e Rio Grande do Sul, no Brasil.

\section{MATERIAL E MÉTODOS}

Foram realizadas coletas mensais totalizando 198 amostras oriundas de lesões em diversas áreas do organismo dos seguintes mamíferos marinhos: Baleia Franca (Eubalaena australis), Baleia de Bryde (Balaenoptera edeni), Baleia Jubarte (Megaptera novaeangliae), Baleia Minke (Balaenoptera acutorostrata), Baleia Bicuda de True (Mesoplodon mirus), Boto Amarelo (Pontoporia blainvillei), Boto Cinza (Sotalia fluviatilis), Golfinho Pintado do Atlântico (Stenella frontalis), Golfinho Comum (Delphinus delphis) e Leão Marinho (Otaria byronia).

As amostras foram coletadas por profissionais do Departamento de Endemias da Escola Nacional de Saúde Pública Sérgio Arouca (DEENSP-FIOCruz), Grupo de Estudos de Mamíferos Aquáticos (GEMARS) e Centro de Estudos Costeiros Limnológicos e Marinhos (Ceclimar), os quais realizam pesquisa baseada em inventário biológico, manejo e recuperação de animais que aportam em nossa zona litorânea. Em seguida, as amostras foram remetidas ao Laboratório de Enterobactérias, Departamento de Bacteriologia, Instituto Oswaldo Cruz (FIOCruz), sendo executadas as análises microbiológicas.

As amostras recebidas foram semeadas em meio Água Peptonada Alcalina (APA) adicionada de $1 \%$ de cloreto de sódio $(\mathrm{NaCl})$ e APA $3 \%$ $\mathrm{NaCl}\left(37^{\circ} \mathrm{C} / 18-24\right.$ horas). Após esse período procedeu-se a semeadura em Ágar TCBS (Tiossulfato Citrato Bile Sacarose) e incubação a $37^{\circ} \mathrm{C}$ por 24 horas. As colônias suspeitas (5-10) fermentadoras ou não de sacarose foram repicadas para meios de triagem (Kligler Iron Agar e Lysine Iron Agar) e Agar Nutriente acrescido de 1\% NaCl. Após a seleção das cepas citocromo-oxidase positivas, foram realizados testes bioquímicos, baseados na resistência ao agente vibriostático $\mathrm{O} /$ 129 (2,4 diamino-6, 7 diisopril-pteridina), produção de ONPG ( $\alpha$ nitrofenil-®-D galactosidase), produção de acetoína em meio VogesProskauer, fermentação da glicose, sacarose, arabinose e manose e utilização de aminoácidos (lisina e ornitina descarboxilase e arginina dehidrolase) a fim de obter a identificação conclusiva das cepas isoladas (FDA 1992).

\section{RESULTADOS E DISCUSSÃO}

No cômputo geral, foram identificadas 108 cepas bacterianas, distribuídas em 17 espécies de Vibrio, tendo sido $V$. alginolyticus, $V$. parahaemolyticus, $V$. vulnificus e $V$. fluvialis aquelas de maior prevalência. Com relação às amostras oriundas de baleias observou-se a predominância de Vibrio alginolyticus (26\%) e V. vulnificus $(17,4 \%)$. Foram isoladas cepas de $V$. parahaemolyticus e $V$. fluvialis, considerados microrganismos de relevância epidemiológica para a saúde pública (Quadro 1).

Quadro 1. Freqüência de Vibrio spp. isoladas a partir de lesões em baleias capturadas no litoral do Rio de Janeiro e Rio Grande do Sul, Brasil, 2005

\begin{tabular}{lcccccc}
\hline \multicolumn{1}{c}{ Microrganismo } & \multicolumn{5}{c}{ Baleias } & \multirow{2}{*}{ Total } \\
\cline { 2 - 6 } & Franca & Bryde & Jubarte & Minke & True & \\
\hline V. alginolyticus & - & - & - & 1 & 5 & 6 \\
V. carchariae & - & - & - & 2 & - & 2 \\
V. vulnificus & - & 1 & 1 & 1 & 1 & 4 \\
V. parahaemolyticus & 1 & - & - & - & 1 & 2 \\
V. cincinnatiensis & 1 & - & 1 & - & - & 2 \\
$V$. fluvialis & 1 & - & - & - & 1 & 2 \\
Vibrio sp. & - & - & - & 1 & 4 & 5 \\
Total & 3 & 1 & 2 & 5 & 12 & 23
\end{tabular}

Analisando os resultados obtidos, observou-se que a espécie Baleia de True apresentou maior diversidade de Vibrio spp. Por outro lado, para Baleia de Bryde isolou-se Vibrio vulnificus, microrganismo de importância para a sanidade animal e humana. A partir das amostras de Leão Marinho foi observado isolamento de $V$. aestuarinus e $V$. pelagius biogrupo II. As amostras oriundas dos botos e golfinhos apresentaram significativa frequiência de $V$. alginolyticus $(16,5 \%)$ e $V$. carchariae $(10,5 \%), V$. parahaemolyticus $(9,4 \%)$ e V. vulnificus $(4,7 \%)$ (Quadro 2 ).

Os mamíferos aquáticos são animais sensíveis às mudanças em seu habitat e por esse motivo considerados excelentes indicadores de saúde em programas de monitorização ambiental. Mudanças climáticas ocasionadas desde a década de 1990 e associadas ao fenômeno El Nino, têm causado o aumento da mortalidade de peixes afetando o ecossistema marinho (Koelle et al. 2005, MMWR 2005). A redução da oferta de alimentos força o deslocamento dos mamíferos marinhos para zonas muito afastadas de seu nicho ecológico natural, favorecendo a pesca predatória indiscriminada, a captura acidental em redes de pesca ou situações de encalhe em bancos de areia. Este aspecto, associado à poluição ambiental e outras modificações antropogênicas, contribui para o aumento da possibilidade de veiculação de patógenos de habitat aquático (Cavalcanti 2003, Davis et al. 2004, MMWR, 2005).

No presente estudo, a diversidade de microrganismos isolados entre os mamíferos marinhos pode ser avaliada sob dois aspectos: como agente causal de enfermidades, em particular nas espécies que não possuem a região tropical como habitat e que aqui aportam a partir de correntes marinhas, 
Quadro 2. Freqüência de Vibrio spp. isoladas a partir de lesões em botos, golfinhos e leão marinho capturados no litoral do Rio de Janeiro e Rio Grande do Sul, Brasil, 2005

\begin{tabular}{|c|c|c|c|c|c|c|}
\hline \multirow[t]{2}{*}{ Microrganismo } & \multicolumn{2}{|c|}{ Boto } & \multicolumn{2}{|c|}{ Golfinho } & \multirow{2}{*}{$\begin{array}{c}\text { Leão } \\
\text { Marinho }\end{array}$} & \multirow[t]{2}{*}{ Total } \\
\hline & Amarelo & Cinza & Pintado & Comum & & \\
\hline V. alginolyticus & 8 & 4 & 2 & - & - & 14 \\
\hline V. carchariae & 9 & - & - & - & - & 9 \\
\hline V. vulnificus & 2 & 2 & - & - & - & 4 \\
\hline V. parahaemolyticus & 5 & 2 & - & 1 & - & 8 \\
\hline V. cincinnatiensis & 2 & - & - & - & - & 2 \\
\hline V. fluvialis & 1 & - & - & - & - & 1 \\
\hline V. furnisii & 2 & - & - & - & - & 2 \\
\hline V. damsela & - & 1 & - & - & - & 1 \\
\hline V. mimicus & - & 2 & - & 3 & - & 5 \\
\hline V. orientalis & 1 & - & - & - & - & 1 \\
\hline V. harveyi & 1 & 4 & - & 1 & - & 6 \\
\hline V. mediterranei & 1 & - & - & - & - & 1 \\
\hline V. aestuarinus & 3 & 1 & - & - & 2 & 6 \\
\hline V. gazogenes & 4 & - & - & - & & 4 \\
\hline V. pelagius I & - & 1 & - & 1 & - & 2 \\
\hline V. pelagius II & - & - & 1 & 1 & 1 & 3 \\
\hline V. campbelii & - & 1 & - & - & - & 1 \\
\hline Vibrio sp. & 9 & 3 & 1 & 1 & 1 & 15 \\
\hline Total & 48 & 21 & 4 & 8 & 4 & 85 \\
\hline
\end{tabular}

ou ainda como oportunistas, em função de condições de estresse dos mamíferos (Thompson et al. 2004).

A ampliação dos conhecimentos sobre os agentes etiológicos de processos infecciosos em mamíferos aquáticos, em particular com relação à patógenos exóticos introduzidos em áreas incólumes, em sua maioria devido aos hábitos migratórios de animais marinhos, poderá contribuir positivamente para a criação de sistemas contínuos de vigilância microbiológica. Essas atitudes podem auxiliar os programas de preservação ambiental, uma vez que algumas das espécies de animais avaliadas encontramse ameaçadas de extinção (Baker et al. 1983).

\section{REFERÊNCIAS}

Baker D.A., Smitherman R.O. \& McCaskey T.A. 1983. Longevity of Salmonella typhimurium in Tilapia aurea and water from pools fertilized with swine waste. Appl. Environ. Microbiol. 45:1548-1558.

Cavalcanti A.D. 2003. Monitoramento da contaminação por elementos traço em ostras comercializadas em Recife, Pernambuco, Brasil. Cad. Saúde Publ. 19:1545-1551.

Davis C.R., Heller L.C., Peak K.K., Wingfield, D.L., Goldstein-Hart, C.L., Bodager, D.W., Cannons, A.C., Amuso, P.T., Cattani, J, 2004. Real-Time PCR detection of the Thermostable Direct Hemolysin and Thermolabile Hemolysin genes in a Vibrio parahaemolyticus cultured from mussels and mussel homogenate associated with foodborne outbreak. J. Food. Prot. 67:1005-1008.

Food and Drug Administration (FDA) 1992. Bacteriological analytical manual. $7^{\text {th }}$ ed. Association of Official Analytical Chemists (AOAC), Arlington, Va, 529p.

Johnson S., Lowenstine L., Gulland R, Jang, S, Imai, D., Almy, F., Delong, R., Gardner, I. 2006. Aerobic bacterial flora of the vagina and prepuce of California sea lions (Zalophus californianus) and investigation of associations with urogenital carcinoma. Vet Microbiol. 114:94-103.

Koelle K., Pascual M. \& Yunus M. 2005. Pathogen adaptation to seasonal forcing and climate change. Proc. Biol. Sci. 272:971-977.

MMWR 2005. Morbidity And Mortality Weekly Report. Vibrio illnesses after hurricane Katrina-Multiple States, August-September 2005. http:// www.cdc.gov/mmwr/preview/mmwrhtml/mm5437a5.htm acesso em 1.11.2005.

Pereira C.S. 2003. A cultura de mexilhões na Baía de Guanabara e suas implicações para a Saúde Pública - Contexto Político-Social e Microbiológico. Tese de doutorado, Escola Nacional de Saúde Pública Sérgio Arouca, Rio de Janeiro, RJ. 176p.

Rodrigues D.P., Ribeiro R.V. \& Hofer E. 1992. Analysis of some virulence factors of Vibrio vulnificus isolated from Rio de Janeiro, Brazil. Epidemiol. Infect. 108:463-467.

Rodrigues S.M.A., Gonçalves E.G.R., Mello D.M., Oliveira, E.G. \& Hofer, E. 2001. Pesquisa de bactérias do gênero Vibrio em feridas cutâneas de pescadores do município de Raposa-MA. Revta Soc. Bras. Med. Trop. 34:407-411.

Thompson F.L., lida T \& Swings J. 2004 Biodiversity of Vibrios. Microbiol. Mol. Biol. Rev. 68:403-431. 